\title{
EXPERIMENTAL RESEARCH OF THE PLASMA ARC CUTTING PROCESS
}

\author{
Dr Anđela Lazarević* \\ University of Niš, Faculty of Mechanical Engineering, Niš, Serbia
}

The results of the experimental research of plasma cutting process were presented in this paper. The impact analysis of the input process parameters: cutting current (I), cutting speed ( $V$ ) and material thickness (s), on the output process parameters: kerf (sr), surface roughness (RZ) and bevel angle $(\beta)$ was done. The plasma cutting machine (CNC) - type HPm Steel Max 6.25 was used in combination with the plasma cutting unit - type Hypertherm HPR130. The workpiece material was stainless steel X10CrNiMn-16-10-2 (EN 10025). Large numbers of cuts were made using the different machine and plasma cutting unit settings. After process data collection, its analysis was done by the software application MatLab. The results were presented in tables as well as on diagrams, showing particularly dependencies between input and output parameters under various conditions. The objective of this paper was to visualize the influence of input parameters on the output parameters, and to prepare the data for plasma cutting process modelling, using different methods: statistical and artificial intelligence.

Key words: Plasma cutting process, Experimental research, Kerf, Surface roughness, Bevel angle

\section{INTRODUCTION}

Experimental research provides the data needed for different kinds of analysis and considerations of events and processes, in order to generate useful information for complex problem solving, especially in the case of unknown process mechanisms. Plasma cutting process modelling, with the respect to the selected modelling method, requires certain number of experiments. Measuring of output parameters based on different sets of input parameters provides the information needed to understand process mechanisms, in accordance with "black box" principle.

For the experimental research, the workpiece material was selected: X10CrNiMn-16-10-2 (EN 10025), with the following chemical composition: $0.1 \% \mathrm{C} ; 16 \% \mathrm{Cr} ; 10 \% \mathrm{Ni}$ and $2 \% \mathrm{Mn}$. Five different workpiece thicknesses were used: 4, 6, 8, 12 and 15 [mm].

For cutting this particular material, three different cutting currents could be used: $45 \mathrm{~A}, 80 \mathrm{~A}$ and $130 \mathrm{~A}$, in accordance with the manufacturer's instructions. Their application is constrained by material thickness ranges, besides following the recommendations for other parameters settings. Since certain thicknesses could be cut using different cutting currents, cutting speed was selected based on the kind and thickness of the material, at particular cutting current. For each material thickness cutting was done using all available recommended cutting currents (since the machine did not allowed continues changes), while, based on the material thickness (s) and selected cutting current (I), cutting speed was determined. The metering was done for all basic elements of the cut quality: kerf (sr), surface roughness (RZ) and bevel angle ( $\beta)$. The values of three input parameters were varying during 99 experiments, and samples were prepared for the examination.

The experimental research was done on CNC machine HPm Steel Max 6.25 (produced by Italian manufacturer High Performance Machinery). Plasma cutting unit used on this machine was Hypertherm HPR130. CNC machine is located in the production facility of the company EM DIP from Niš [01].

CNC machine in combination with adequate plasma cutting unit provides high quality and precise cuts, with extended life cycle of the consumables. Software used to operate and control CNC machine was adapted to the users' needs and fully programmed and constrained by the manufacturer's recommendations for the selection of cutting conditions and parameters. There 
fore, it is almost impossible to select the working parameters that could produce low quality cut or harm the machine or plasma cutting unit.

The dimensions of the working table are 4,000 and $2,000 \mathrm{~mm}$, with the $\mathrm{x}$ and $\mathrm{y}$ axes positioning precision of $+/-0.1 \mathrm{~mm}$. The adaptable moving along the axes could develop speeds of 60 $\mathrm{m} / \mathrm{min}$, while in the case of plasma cutting and the particular plasma cutting unit Hypertherm HPR130 cutting speeds should not exceed $8 \mathrm{~m} /$ min [02]. There are movable drawers under the coordinate table, which provide fast and efficient removal of the waste material. CNC machine also have the ventilation system, in order to inhale smoke from the cutting area. The CNC Machine is also equipped with the Automatic Torch Height Control, which provides constant distance between cutting torch and workpiece by voltage control $[03,04]$.

Plasma cutting unit Hypertherm HPR130 can cut the material thicknesses up to $38 \mathrm{~mm}$ for mild steel and $25 \mathrm{~mm}$ for stainless steel and aluminium. In accordance with the manufacturer's specification, the characteristics of the plasma cutting unit are given in the Table 1.

Table 1: The basic characteristics of the plasma cutting unit Hypertherm HPR130

\begin{tabular}{|c|c|}
\hline Power & $19,5 \mathrm{~kW}$ \\
\hline \multirow{2}{*}{$\begin{array}{c}\text { Input voltage and current } \\
\text { (Alternate current) }\end{array}$} & $200 / 208 ; 220 ; 240 ; 380 ; 400 ; 440 ; 480 ; 600 \mathrm{~V}$ \\
\cline { 2 - 2 } & $50 / 60 ; 50 / 60 ; 60 ; 50 / 60 ; 50 / 60 ; 60 ; 60 ; 60 \mathrm{~Hz}$ \\
\cline { 2 - 2 } & $62 / 58 ; 58 ; 52 ; 34 ; 32 ; 28 ; 26 ; 21 \mathrm{~A}$ \\
\hline \hline Cutting voltage (Direct current) & $50-150 \mathrm{~V}$ \\
\hline Cutting current range & $30-130 \mathrm{~A}$ \\
\hline Maximum OCV (Open Cycle Voltage) & $311 \mathrm{~V}$ \\
\hline Dimensions & $1079,5 \mathrm{~mm} \times 566,4 \mathrm{~mm} \times$ 967,7 mm \\
\hline Weight with torch & $317,5 \mathrm{~kg}$ \\
\hline Gas supply & O2; N2; F5; H35; Air \\
\hline Plasma gas & $\mathrm{N} 2 ;$ O2; Air \\
\hline Shield gas & \\
\hline
\end{tabular}

CNC control unit provides monitoring of the work plans and cutting trajectory via screen, which allows complete and automatic directing of the torch movements. CNC control unit can also receive information related to manufacturing process from the remote computer, which should be followed by the input parameters setting. All cutting parameters could be modified during cutting process.

\section{MEASURED PARAMETERS AND METERING EQUIPMENT}

For the experimental purposes, rectilinear cuts were made by the abovementioned plasma cutting machine, varying the input parameters (cutting current, cutting speed and material thickness) chosen as independent variables for the purpose of process modelling. Figure 1 shows the experimental setup, together with the control screen.

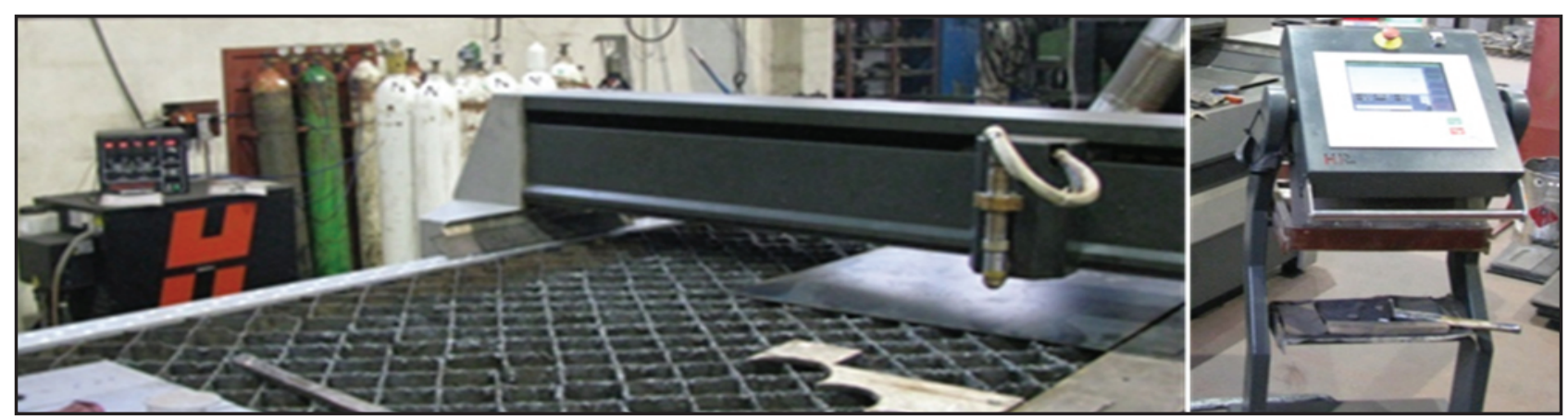

Figure 1: View of the experimental setup 
The rectilinear cuts were of the same length, while plasma jet starts cutting from the point inside the workpiece moving toward the outer part of the material. Figure 2 shows samples prepared for examination. The samples were prepared by cutting the metal table containing experimental cuts perpendicularly on the cuts, after complete cooling of the table. On this way, the samples were separated from the workpiece table, which were then used for the output parameters metering. Selected experimental samples were presented at Figure 3, for different material thicknesses.

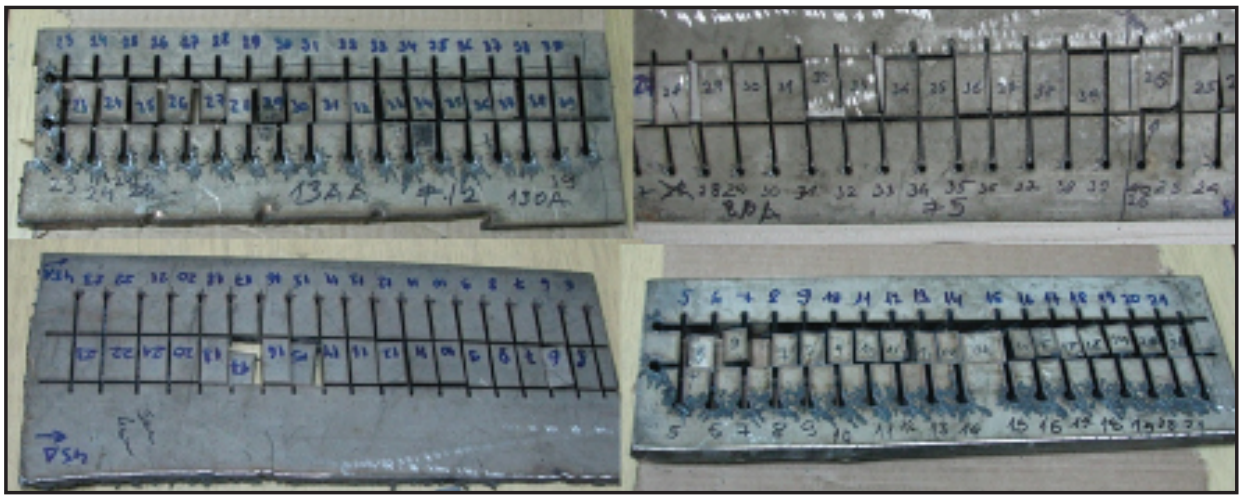

Figure 2: Samples prepared for examination

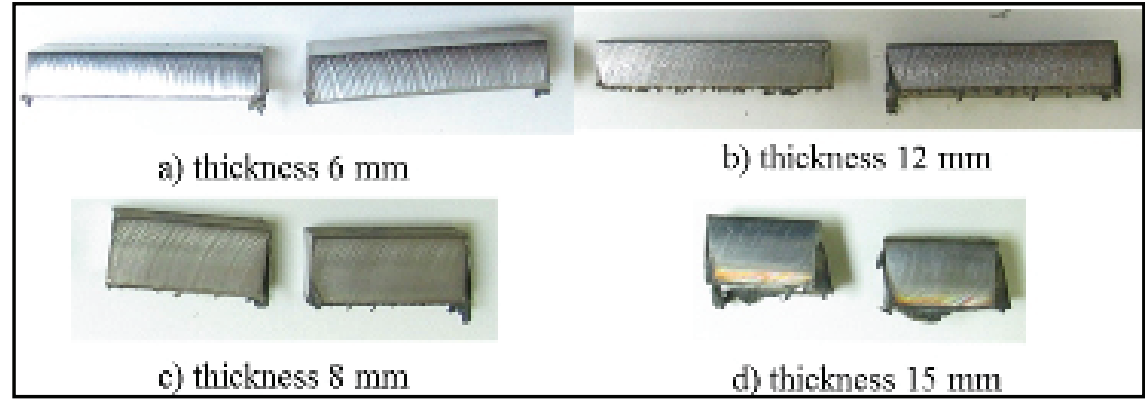

Figure 3: View of the sides of cut for different thicknesses

The metering of the basic elements of the cut quality: kerf width (sr), surface roughness (RZ) and bevel angle $(\beta)$ was done. The kerf width metering was done using the digital calliper Mitutoyo, number 330610, made in Japan, with the metering range from 0.01 to $150 \mathrm{~mm}$ and precision of $0.01 \mathrm{~mm}$. Bevel angle was metered by the optical angle meter Carlzeiss, made in Switzerland, with the precision of 5 angle minutes. The surface roughness was metered by the Mitutoyo Portable Surface Roughness Tester, Type SJ 301 [05].

\section{THE RESULTS OF THE EXPERIMENTAL RESEARCH}

The metering results of the 99 cuts were grouped with respect to the material thickness and presented in the table, which allowed its easier graphical representation. The following diagrams present the experimental results with respect to the material thickness together with the linear approximation of the experimental data [06].
Therefore, Figure 4 shows the kerf width dependences of the cutting speeds, for the material thickness $s=4 \mathrm{~mm}$ and cutting currents: $I=45 \mathrm{~A}$ and $I=80 \mathrm{~A}$. It shows that higher cutting speeds imply smaller kerf widths. Kerf width depends also on the cutting current. Lower cutting current produce smaller kerf width. While cutting materials using lower cutting currents, the decrease in kerf width is more significant.

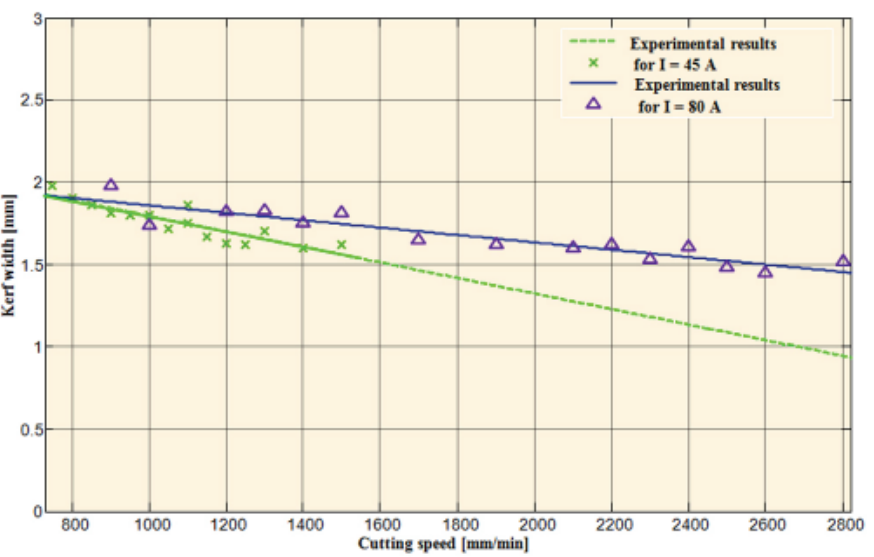

Figure 4: The kerf width dependency of the cutting speed, material thickness $s=4 \mathrm{~mm}$, cutting current $I=45 \mathrm{~A}$ and $\mathrm{I}=80 \mathrm{~A}$ 
Figure 5 shows the surface roughness dependences of the cutting speeds, for the material thickness $\mathrm{s}=4 \mathrm{~mm}$ and cutting currents: $\mathrm{I}=45 \mathrm{~A}$ and I=80 A. It shows that higher cutting speeds imply higher surface roughness. This trend is more pronounced in cutting smaller material thicknesses. Also, the use of lower cutting currents leads to the higher surface roughness.

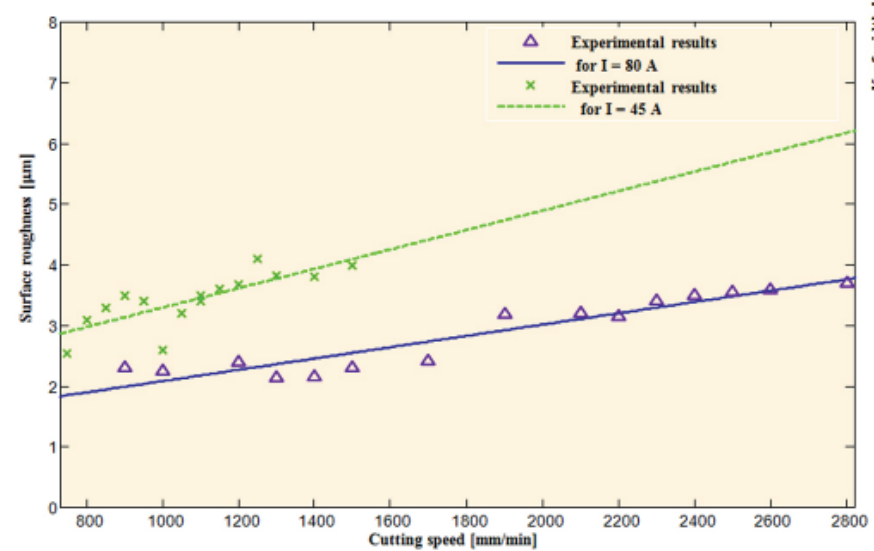

Figure 5: Surface roughness dependency of the cutting speed, material thickness $s=4 \mathrm{~mm}$, cutting current $I=45 \mathrm{~A}$ and $\mathrm{I}=80 \mathrm{~A}$

Figure 6 shows the bevel angle dependences of the cutting speeds, for the material thickness $\mathrm{s}=4 \mathrm{~mm}$ and cutting currents: $\mathrm{I}=45 \mathrm{~A}$ and $\mathrm{I}=80 \mathrm{~A}$. It shows that higher cutting speeds imply bigger bevel angle, while the value of the bevel angle is higher during cutting using smaller material thicknesses.

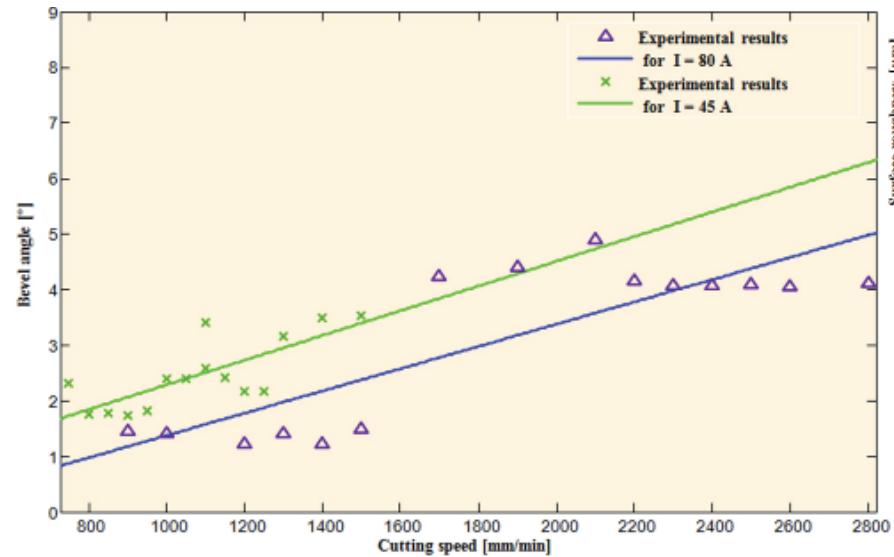

Figure 6: Bevel angle dependency of the cutting speed, material thickness $s=4 \mathrm{~mm}$, cutting current $I=45 \mathrm{~A}$ and $\mathrm{I}=80 \mathrm{~A}$

Figure 7 shows the kerf width dependences of the cutting speeds, for the material thickness $\mathrm{s}=6 \mathrm{~mm}$ and cutting currents: $\mathrm{I}=45 \mathrm{~A}$ and $\mathrm{I}=80 \mathrm{~A}$. It shows that higher cutting speeds imply smaller kerf widths. Lower cutting current produce small- er kerf width. The impact of the different cutting currents is less significant while cutting thicker materials using higher cutting speeds.

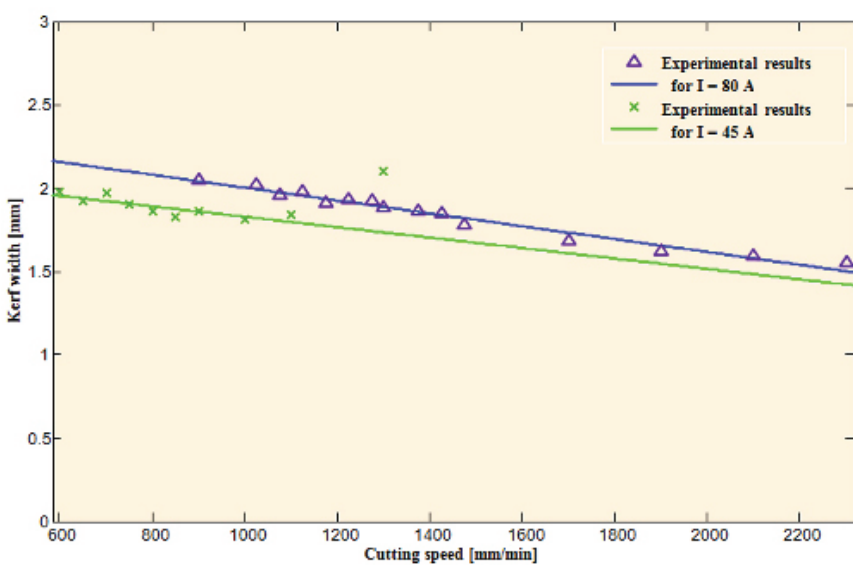

Figure 7: The kerf width dependency of the cutting speed, material thickness $s=6 \mathrm{~mm}$, cutting current $I=45 \mathrm{~A}$ and $\mathrm{I}=80 \mathrm{~A}$

Figure 8 shows the surface roughness dependences of the cutting speeds, for the material thickness $\mathrm{s}=6 \mathrm{~mm}$ and cutting currents: $\mathrm{l}=45 \mathrm{~A}$ and $\mathrm{I}=80 \mathrm{~A}$. As in Figure 5, higher cutting speeds imply higher surface roughness. However, this impact is less significant while cutting thicker materials. It was also noticed that the value of the surface roughness is smaller while cutting thicker materials.

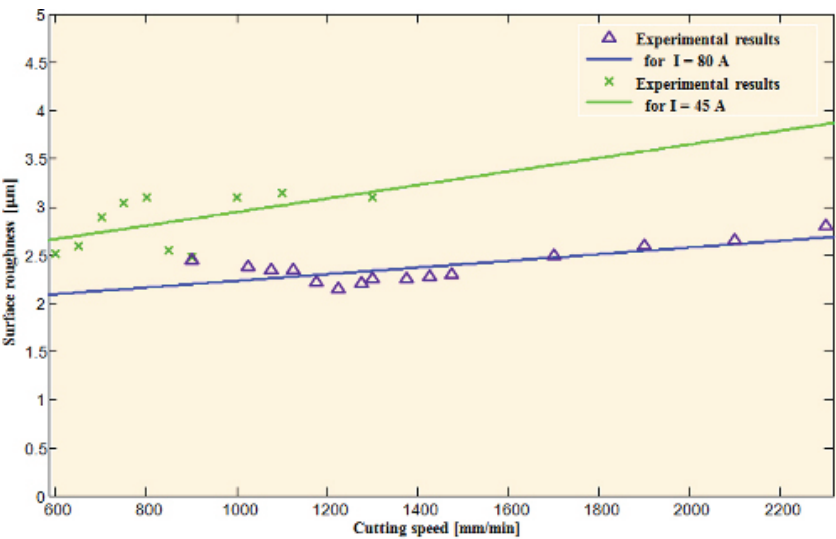

Figure 8: Surface roughness dependency of the cutting speed, material thickness $s=6 \mathrm{~mm}$ cutting current $I=45 \mathrm{~A}$ and $\mathrm{I}=80 \mathrm{~A}$

Figure 9 shows the bevel angle dependences of the cutting speeds, for the material thickness $\mathrm{s}=6 \mathrm{~mm}$ and cutting currents: $\mathrm{I}=45 \mathrm{~A}$ and $\mathrm{I}=80$ A. The bevel angle increasing trend with cutting speed increasing is the same as in the case of lower material thicknesses. However, the values of bevel angle are lower than in case of cutting smaller material thicknesses. 


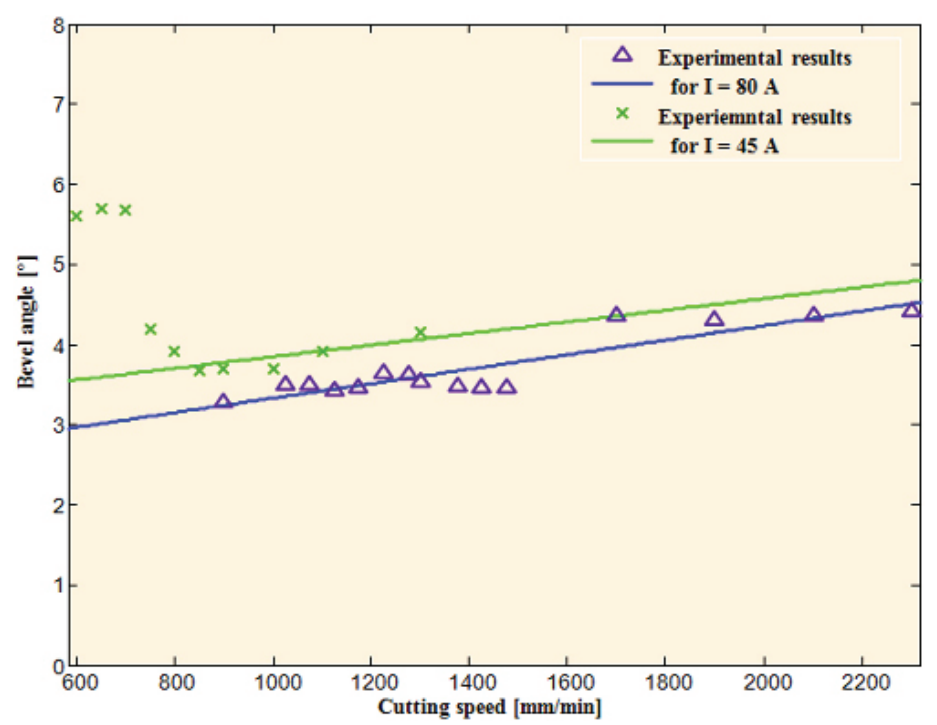

Figure 9: Bevel angle dependency of the cutting speed, material thickness $s=6 \mathrm{~mm}$, cutting current $\mathrm{I}=45 \mathrm{~A}$ and $\mathrm{I}=80 \mathrm{~A}$

Figure 10 shows the kerf width, surface roughness and bevel angle dependences of the cutting speeds, for the material thickness $\mathrm{s}=8 \mathrm{~mm}$ and cutting current $\mathrm{I}=80 \mathrm{~A}$.

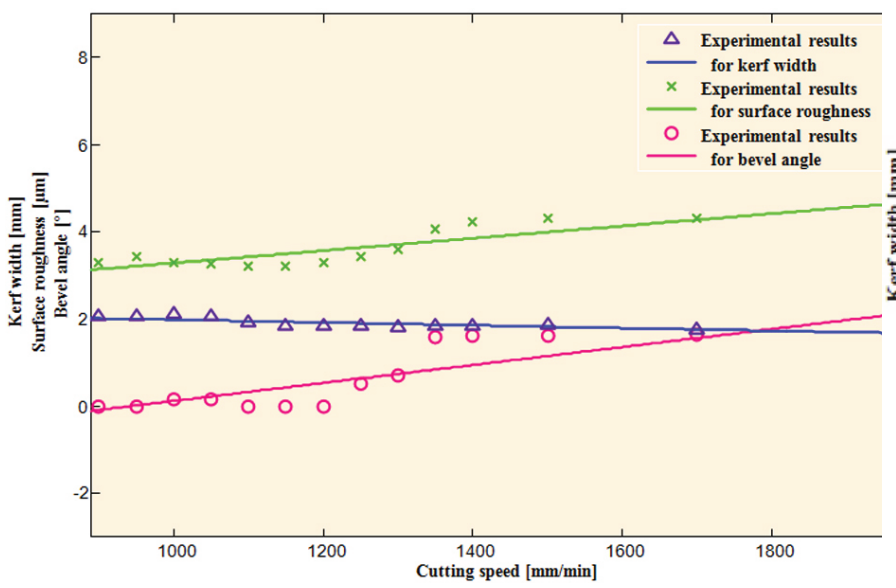

Figure 10: The kerf width, surface roughness and bevel angle dependencies of the cutting speed, for the material thickness $s=8 \mathrm{~mm}$, cutting current I=80 A

Figure 11 shows the kerf width, surface roughness and bevel angle dependences of the cutting speeds, for the material thickness $\mathrm{s}=12 \mathrm{~mm}$ and cutting current $\mathrm{I}=130 \mathrm{~A}$. Since this was the case of cutting thick workpiece material, the cutting current used during this experiment was high in order to provide successful cutting. As in the previous analysis of the experimental results, the increase in cutting speed implies the increase in surface roughness and bevel angle. However, these trends are less pronounced in the case of thicker materials and bigger cutting currents. Figure 11 also shows that higher cutting speeds imply smaller kerf widths.

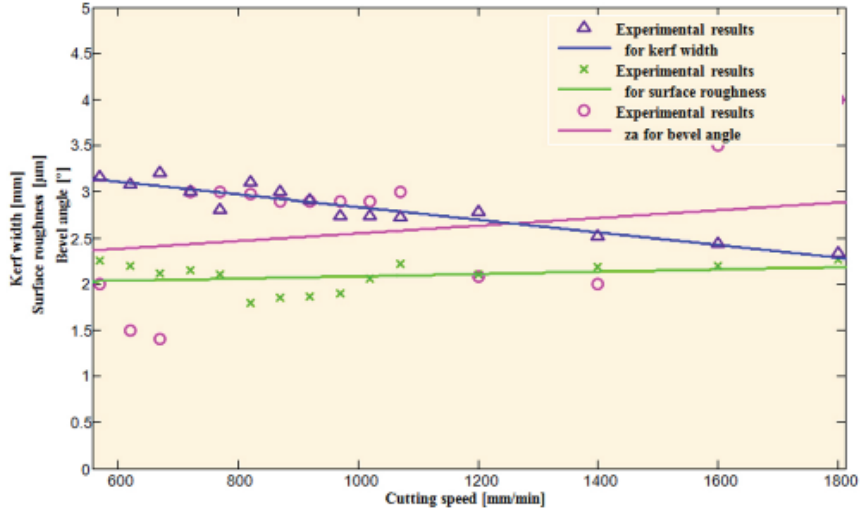

Figure 11: The kerf width, surface roughness and bevel angle dependencies of the cutting speed, for the material thickness $s=12 \mathrm{~mm}$ and cutting current $\mathrm{I}=130 \mathrm{~A}$

Figure 12 shows the kerf width, surface roughness and bevel angle dependences of the cutting speeds, for the material thicknesses $=15$ $\mathrm{mm}$ and cutting current $\mathrm{I}=130 \mathrm{~A}$. For this thicker material it could be concluded that by increasing the cutting speed previous trends are less pronounced.

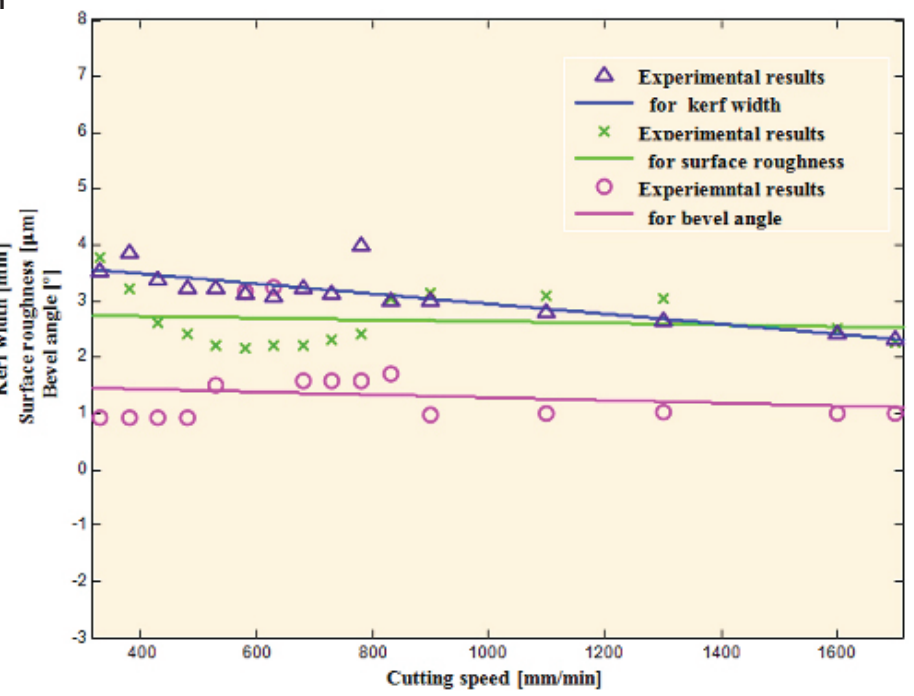

Figure 12: The kerf width, surface roughness and bevel angle dependencies of the cutting speed, for the material thickness $s=15 \mathrm{~mm}$ and cutting current $\mathrm{I}=130 \mathrm{~A}$

\section{CONCLUSION}

The experimental research provided data necessary for further analysis and considerations of the plasma cutting process. This data were used for plasma cutting process modelling, using different methods, while not all data should be used for every modelling method. Data graphical representation provided the visual insight in the dependencies that exist among data.

Metering of the output process parameters for different combination of the input parameters provided the information needed to understand 
the plasma cutting process mechanisms. However, the software application used for the process control constrained some variations of the input parameters in accordance with the machine manufacturer's recommendations. The flexibility in input parameters selection was limited, and it would be useful for the further considerations to predict wider ranges of input parameters changes, for the purposes of the data analysis and monitoring of parameters interdependences.

This paper provided visualization of the input parameters impact to the process output parameters and, therefore, data preparation for the plasma cutting process modelling using different statistical and/ or artificial intelligence methods.

\section{ACKNOWLEDGEMENTS}

This paper was done in the scope of the projects: TR35034 "The research of modern non-conventional technologies application in manufacturing companies with the aim of increase efficiency of use, product quality, reduce of costs and save energy and materials", and TR33040 " Revitalization of existing and designing of new micro and small hydro power plants (from 100 to 1.000 $\mathrm{KW}$ ) at the territory of south and south-east Serbia", funded by the Ministry of Education and Science, Republic of Serbia.

\section{REFERENCES}

1) Lazarevic A., (2010) Modelling of the parameters correlations of the plasma arc cutting process and analysis of the process energy balance by applying artificial intelligence methods, Doctoral dissertation, Faculty of Mechanical Engineering, University of Nis.

2) Colt J., (2014) The High-Definition Revolution in Plasma Cutting, Hypertherm, Inc., Fabrication magazine.

3) D. Cook, (2000) Illustrated guide to plasma gas selection - How to choose the best gases, Welding Design and Fabrication.

4) D. Cook, (2000) Solving PAC problems - Quality problems Dross, Welding Design and Fabrication.

5) Rančić B., (1999) Praktikum za laboratorijske vežbe iz inženjerske metrologije sa teorijskim osnovama, Mašinski fakultet, Univerzitet u Nišu.

Paper sent to revision: 19.09.2014.

Paper ready for publication: 12.12.2014. 